\title{
INTEGRATED PRODUCT AND ENTERPRISE DESIGN FOR GLOBAL COMPETITIVENESS
}

\author{
Prof ND du Preez, JMC Reid \\ Dept of Industrial Engineering \\ University of Stellenbosch \\ South Africa
}

\begin{abstract}
This paper presents an overview of the challenge to integrate product and process life cycles in maintaining global competitiveness of an enterprise and proposes IEKOS as a possible solution. It provides the reader with a framework of two virtual life cycles which create a problem solving matrix for the industrial engineer. In this matrix, bordered by the virtual enterprise life cycle and the virtual product life cycles, the business functions of analyze, design deploy and operate are predominantly functions executed by the industrial engineer. The different phases of each life cycle serves as a framework to a virtual industrial engineering toolkit providing access to detailed functions, formats, examples and a series of software and other "tools" available to the industrial engineer.
\end{abstract}

In conclusion a brief overview is provided of the progress of the IEKOS toolkit which is under development at the department of Industrial Engineering at Stellenbosch University.

Keywords. Agility, Integration, Enterprise Design, Product Design, design support, life cycle.

\section{Introduction}

Recent Improvements in communication and Information Technology and a reduction in protective control on local markets have lead to a continuous increase in the level of global competitiveness in the manufacturing industry. It is becoming increasingly challenging to beat ones competition in the race for client orders. Survival in the manufacturing marketplace depends largely on agility and integrated effort within integrated enterprises. Forming Alliances with other service providers and fully understanding the value chain has become a necessity.

The increase in complexity of product and enterprise design as an integrated whole rather than as two separate processes has led to the development of an integrated electronic support platform, the Industrial Engineering Knowledge Object System (IEKOS).

This paper describes the rationale, the focus of research activities and the application thereof in global competition in the manufacturing marketplace. Specific reference will be made to enterprise design methodologies, product design support platforms and the role of Industrial Engineering in integrating enterprises and product designs. 


\section{Product life cyle}

The typical product development life cycle encapsulates the different phases as presented in figure 1. Agile product development requires information from the different phases of development to be available in real time throughout the organization. This facilitates concurrent engineering. The Product Data Management (PDM) system is a technology that enables concurrency and agility of the product development life cycle.

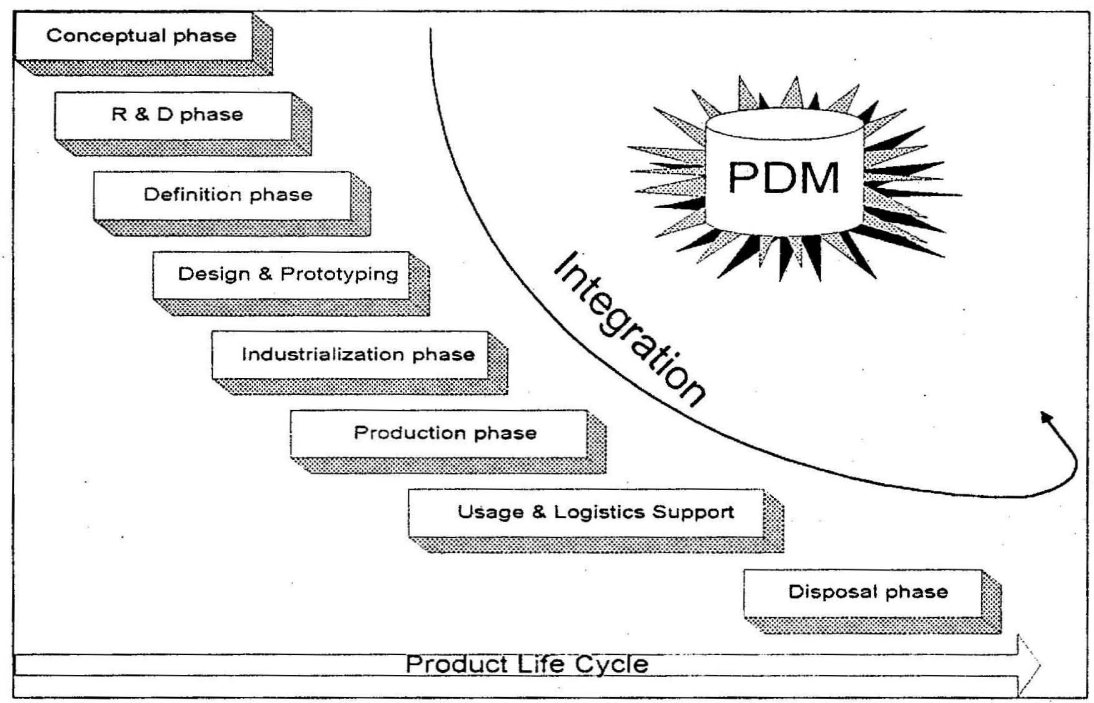

Figure 1: Product Life Cycle with PDM

\section{Enterprise Life Cycle}

The ability to produce products efficiently and effectively however, requires more that just a good understanding of the product life cycle. A thorough understanding of all the processes along the entire value chain and the enterprise in which it exists is needed. We now know that the enterprise life cycle has to posess properties similar to those found in the product life cycle. The enterprise must be agile and posess the ability to restructure itself according to continuously changing market needs. Enterprise engineering is to enterprise design what concurrent engineering is to product design.

The enterprise is however far more complex than any one product. The human component of the enterprise life cycle adds complexity and unpradictability to enterprise design and the shear magnitude of an enterprise wide project can drown the designers and analysts with information. The complexity of the enterprise design procedure focusing on manufacturing, information as 
well as organisational architectures further increases the format, structure and shear volume of design information. In order to prevent this from happening, only essential information about the enterprise and the enterprise life cycle must be captured This information can then be stored in an Enterprise Data Management ( EDM) system.

The selection of essential information is the key to the success of the EDM system. Fortunately several Enterprise Engineering or redesign methodologies have been developed over the last decade. These methodologies help to structure the design of entire enterprises by providing reference architectures and modelling tools.

The most common of these are CIMOSA, PERA, GRAI-GIM and GERAM (under development). These methodologies all aim to facilitate enterprise integration by providing referance architectures and tools which can be used to break down the enterprise into entities. These entities can then be redesigned seperately and integrated into the enterprise as a whole without breaking down the integration between them. Figure 2 below illustrates a generic enterprise life cycle with the corresponding phases of PERA on the left-hand side.

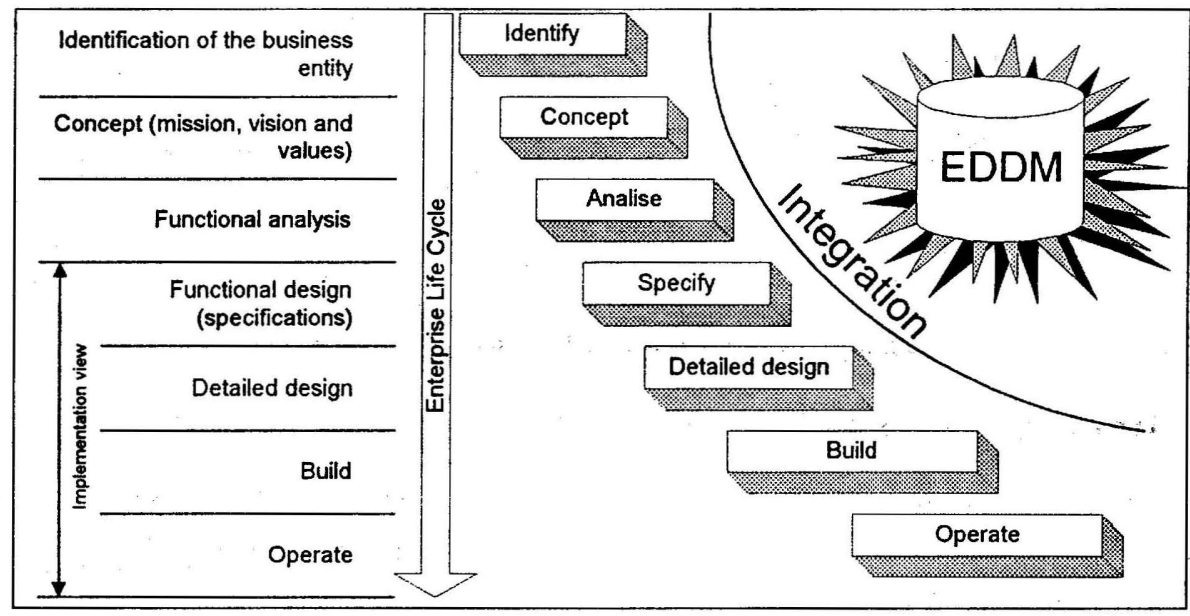

Figure 2: The Virtual Enterprise Life Cycle with the corresponding PERA methodology

Integrated Product / Enterprise Life Cycle

It follows logically that an Enterprise Data Management system can facilitate the enterprise development and restructuring activities. However the enterprise design or restructuring is related to the product design. Thus an integrated product / enterprise life cycle matrix such as the one in Figure 3 below is essential in the competitiveness race. 
The boundaries of enterprises are set to change in the future, with a strong solid core and a much broarder periphery, fluctuating in size and in structure to adapt to changes in the environment.

[World Competitiveness Report 1994]

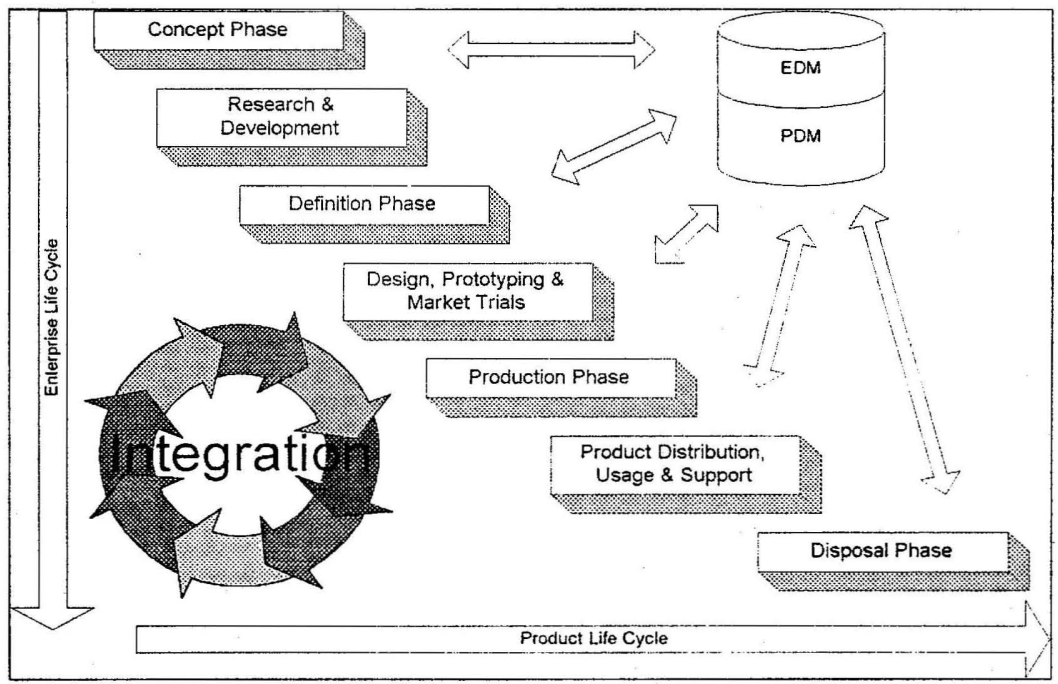

Figure 3: The Enterprise / Product Life Cycle Matrix

\section{IEKOS and the Industrial Engineering Tool kit}

The product and process design activities are by no means a one-person task. It is in essence a multi-disciplinary team activity. Hence the support of the Industrial Engineering Knowledge Object System (IEKOS) and in particular the Industrial Engineering Toolkit makes good engineering sense both for teaching and applying product and enterprise design.

The department of Industrial Engineering at Stellenbosch University initiated the design of the IEKOS environment in 1996. The IEKOS environment provides structure to the disciplines involved in Industrial Engineering. It forms a framework in which vast amounts of information can be stored and easily retrieved and in doing so adds value to the information. IEKOS was developed in the hypertext environment to improve readability and navigation. Hypertext also permits the use of searchable data bases. The data bases, of which IEKOS possesses two, help users optimise their search for information in the system.

The IE Toolkit forms an important part of IEKOS and has received a large amount of attention since the formation of the Group for Enterprise Engineering and Competitiveness (GEEC) late in 
1996. GEEC uses IEKOS as a basis for the dissemination of its research information. The IEKOS system will be made available to external users in April 1998. Accesses to the IEKOS Internet site will however be password controlled and interested parties are encouraged to contact the Department of Industrial Engineering at Stellenbosch University for further details.

The Enterprise Engineering Toolkit, which is the focus of this paper, describes all the phases in the product and the enterprise life cycles from an Industrial Engineering perspective. This is achieved by expanding on the virtual life cycles matrix presented in Figure 4 . The matrix is based on the fact that numerous disciplines are needed to design products and enterprises. In order to be competitive, these disciplines have to work together to achieve the greater whole. It is felt that Industrial Engineers possess the necessary skills to co-ordinate many of the disciplines involved and thus achieve improved competitiveness. The matrix therefore provides a framework within which the Industrial Engineer can co-ordinate many of the disciplines necessary to design products and enterprises. It then goes further to describe the interactions between the disciplines and the functions that have to be performed during design or re-design. The enterprise and product designer can use the information contained in the toolkit to aid in any design or redesign project. The design structure of the IEKOS system and the IE Toolkit is presented in Figure 5.

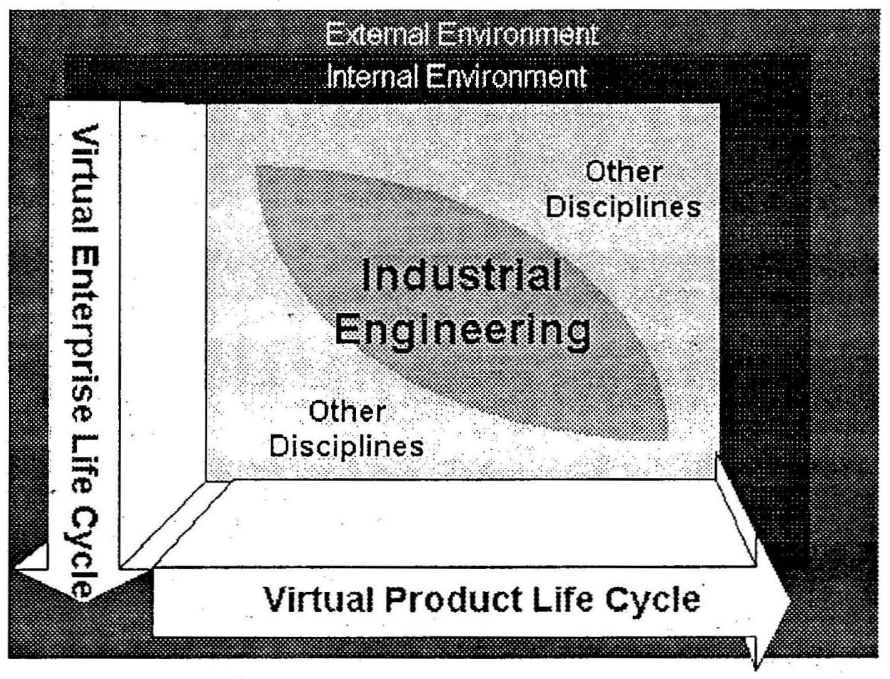

Figure 4: The EI Toolkit life cycle interface matrix

The virtual enterprise life cycle is described using the PERA model. Information is gathered about each of the 28 components in the model. Each components is described in terms of the functions that have to be performed, products and outputs, examples and case studies, tools and 
techniques, and resources and inputs that are used. In this way a generic reference model is built up about all the design components in the enterprise life cycles.

Similarly information is gathered about the virtual product life cycle using a generic product life cycle model. By combining the enterprise and the product information in the life cycle matrix that was introduced in Figure 3, the designer can determine the effect that enterprise design changes will have on the product and vice versa. This is important, because a competitive enterprise consists of good products and a good enterprise. The virtual life cycles matrix allows the designer to work concurrently with product and enterprise design. This improves awareness and makes the enterprise more agile.

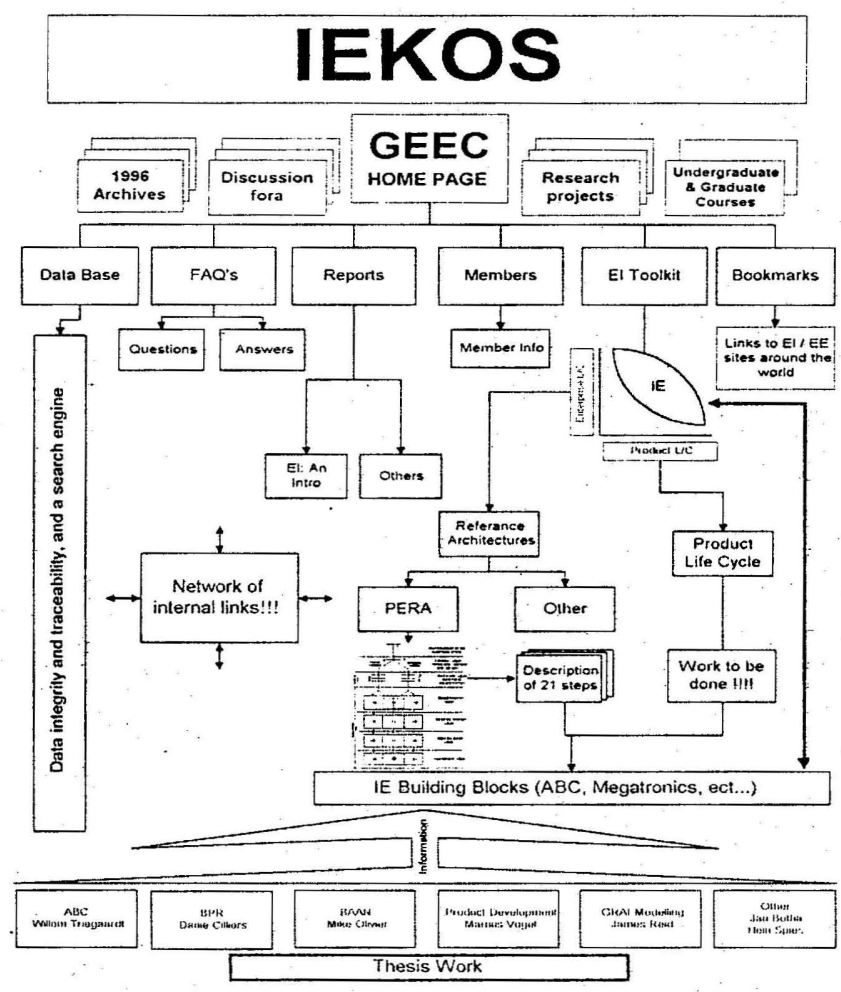

Figure 5: The IEKOS map

At present the virtual enterprise life cycle is described using only the PERA methodology. The PERA model is shown in Figure 6. The toolkit has however been designed to include othe 
methodologies such as GRAI-GIM, CIMOSA and GERAM in the future. The product life cycle is described using the generic life cycle presented in Figure 1.

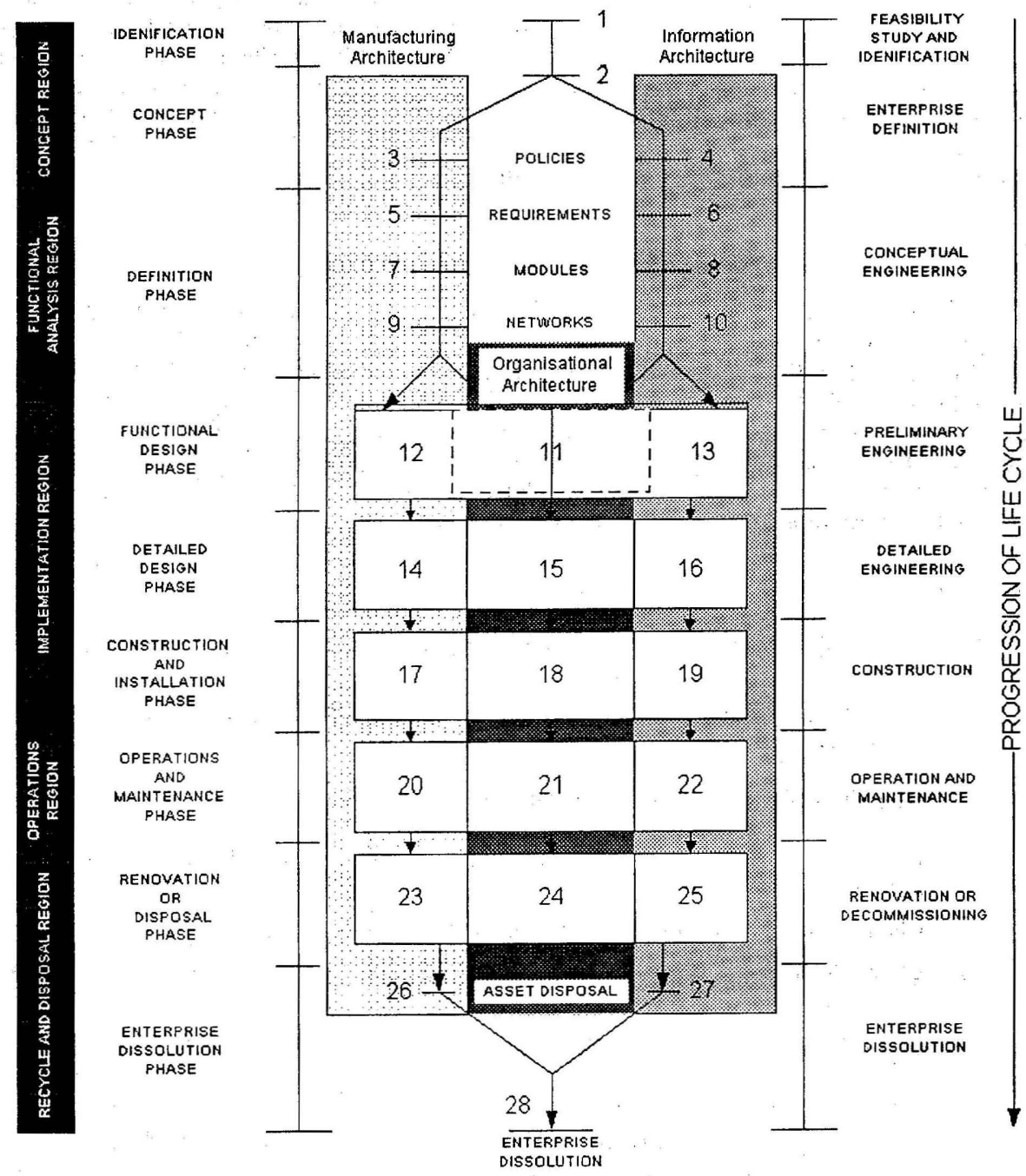

Figure 6: The PERA Model 
The PERA Methodology uses three views or architectures (informational, manufacturing and organisational) to describe the design of the entire enterprise. These views are developed using the 28 components of PERA which follow logically from the model in Figure 6. PERA was chosen for the IE Toolkit because it offers the most logical and complete enterprise design architecture from an Industrial Engineering perspective. The PERA model is used as a map for the 28 components. By clicking on one of the 28 components the user can access more detailed information about the specific component. Similarly the steps in the product life cycle can be clicked on to view more detailed information. In order to integrate the life cycles, reference is made where necessary from the one life cycle to the other.

\section{Conclusions}

The Industrial Engineering Knowledge Object System (IEKOS) is designed to provide enterprise and product analysts and designers with information. A large portion of this information is made up of the research work done by the Group for Enterprise Engineering and Competitiveness, who are responsible for the design and development of the IE Toolkit. GEEC has decided not to join the race to produce a reference architecture or methodology of its own. The emphasis is on understanding and using existing architectures and methodologies in an integrated manner and from an Industrial Engineering perspective. In doing so it is hoped that value will be added to the field of Enterprise Engineering and to the field of Industrial Engineering.

\section{Referençes}

1. Armistead, C. \& Rowland, P.; Managing Business Processes BPR and Beyond; John Wiley \& Sons.

2. Akao, Yoji : Quality Function Deployment, Integrating Customer Requirements into Product Design : 1990.

3. Baan Product Data Management at http://www.baanpdm.com/

4. Bernus, P, Nemes, L \& Williams, J. : Architectures for Linterprise Integration, First Edition 1996.

5. Charnery, Cyril : Time to Market, Reducing Product Lead Time: 1991.

6. Clark, Kim B;. Wheelright, Steven C: Managing New Product and Process Development, Text and Cases : 1993.

7. Doumeingts, G, Vallespir, $\mathrm{B}$, Zanetin, $\mathrm{M}$, Chen, D: GRAI INTEGRATED METHODOLOGY; A methodology for designing (CIM systems, University Bordeaux 1 LAP/GRAI, version 1.0, 1.992

8. Edosomwan, J.A.; Organisational Transformation and Process Re-engineering, The Quality Observer: St. Lucie Press Delray Beach, Florida.

9. Graduate School of Business, South African ('ompetitiveness: A study of the nine provinces, University of Stellenbosch, 1995 
10. Hartley, John R : Concurrent Engineering; Shortening Lead Times, Raising Quality, and Lowering Costs : 1992.

11. IMAN Product Data Management Software at http://www.ug.eds.com/iman/

12. IMD. 1994. The World Competitiveness Report 1994, Lausanne, Switzerland: IMD

13. Rottier, J : The Industrial Engineer as Enterprise Designer, South African Journal of Industrial Engineering, Vol.8 1997

14. Salvendy, G: Handbook of Industrial Engineering, Second Edition, Institute of Industrial Engineering, 1991.

15. Smith, Preston G.; Reinertsen, Donald G. : Developing Products in Half the Time : 1991.

16. Stalk (jr.), George; Hout, Thomas M. : Competing Against Time, How Time-based Competition Is Reshaping Global Markets.

17. Syan, Chanan S; Menon, Unny : Concurrent Engineering, Concepts, Implementation and Practice: 1994.

18. Williams, T.J,Rathwell G.A, Li H. : A Handbook on Master Planning and Implementation for Enterprise Integration Programs, Report Number 160, Purdue Laboratory for Applied Industrial Control: June 1996 